\title{
Dielectric Properties and AC Conductivity of Organic Films of Copper(II) 2,9,16,23-Tetra-tert-butyl-29H,31H- phthalocyanine
}

\author{
A.A.A. DARWISH ${ }^{1,2}$ S.R. ALHARBI, ${ }^{3}$ MUSTAFA M. HAWAMDEH, ${ }^{4}$ \\ ABDULRHMAN M. ALSHARARI ${ }^{1}$ and SALEEM I. QASHOU ${ }^{5,6}$ \\ 1.-Department of Physics and Nanotechnology Research Unit, Faculty of Science, University of \\ Tabuk, Tabuk 71491, Saudi Arabia. 2.-Department of Physics, Faculty of Education at Al- \\ Mahweet, Sana'a University, Al-Mahweet, Yemen. 3.-Department of Physics, Faculty of Science, \\ University of Jeddah, Jeddah, Saudi Arabia. 4.-Department of Physics, Faculty of Science, Al- \\ Balqa Applied University, Al-Salt 19117, Jordan. 5.-Department of Physics, Faculty of Science, \\ Zarqa University, Zarqa 13132, Jordan. 6.—e-mail: sa.i.y.q@hotmail.com
}

\begin{abstract}
Copper(II) 2,9,16,23-tetra-tert-butyl-29H,31H-phthalocyanine (CuTTBPc) thin films have been obtained using a physical vapor deposition technique. $\mathrm{X}$-ray diffraction analysis confirmed their amorphous nature. The dielectric constant and electrical conductivity were measured over the frequency range from $50 \mathrm{~Hz}$ to $8 \mathrm{MHz}$ and temperature range from $293 \mathrm{~K}$ to $393 \mathrm{~K}$. The dependence of the dielectric relaxation spectra on frequency at different temperatures was measured and discussed. In addition, the spectral dynamics of both the real and imaginary parts of the complex electric modulus over a wide temperature range is explained. The activation energy of the relaxation process $\left(\Delta E_{\mathrm{M}}\right)$ was estimated to be $0.26 \mathrm{eV}$. Moreover, the dependence of the alternating current conductivity on both temperature and frequency was investigated. Additionally, the exponent $(s)$ of the power law of conductivity versus temperature confirmed that the correlated barrier hopping $(\mathrm{CBH})$ model is a successful and appropriate mechanism to explain the charge transportation inside CuTTBPc films. According to this model, the density of localized states $N\left(E_{\mathrm{F}}\right)$ at room temperature and frequency of $500 \mathrm{kHz}$ was evaluated to be $4.11 \times 10^{23} \mathrm{eV}^{-1} \mathrm{~cm}^{-3}$. This high density of electron states indicates that CuTTBPc can be recommended as a candidate material for use in solar cells.
\end{abstract}

Key words: Organic film, dielectric relaxation, electrical conductivity

\section{INTRODUCTION}

Although inorganic materials exhibit adequate and appropriate optical and electrical properties, recent research interest has led to the discovery of several small organic molecules with convenient optical and electronic properties. ${ }^{1,2}$ To enable the use of such organic molecules in photoelectronic devices and solar cells, they must exhibit several

(Received July 15, 2019; accepted December 2, 2019; published online December 17, 2019) preferred features such as thermal stability, enhanced electrical conductivity, and affordable simple synthesis. ${ }^{3-6}$ Phthalocyanine (Pc) compounds exhibit these characteristics, leading to wide interest in these materials over the last decade, which has revealed that they acquire unique properties in the presence of atoms of metallic elements such as $\mathrm{Cu}, \mathrm{Al}$, and $\mathrm{Mg} .{ }^{7,8}$ It has been found that Pc materials including a metallic atom (MPc) exhibit excess charge transport, in turn boosting their internal electronic properties; ${ }^{8}$ For example, the density of states and activation energy of aluminum phthalocyanine chloride $(\mathrm{AlPcCl})$ were 
calculated to be $4.11 \times 10^{19} \mathrm{~cm}^{-3}$ and $0.34 \mathrm{eV}$, respectively, ${ }^{7}$ indicating strong charge carrier transport in this material.

In addition, the activation energy of copper phthalocyanine $(\mathrm{CuPc})$ was estimated to be $0.3 \mathrm{eV}$ based on AC conductivity measurements, suggesting a low value of the barrier height, which will allow transfer of hopping charges between the sides of the potential barrier. ${ }^{9}$ On the other hand, CuPc synthesized with peripheral groups showed improved dielectric and electrical conductivity characteristics compared with bare $\mathrm{CuPc}$ compound in several regards, partially due to the excess aggregated mobile charges provided by the peripheral groups. However, cross-linking of $\mathrm{CuPc}$ molecules with peripheral groups predominately changes their molecular structure, effectively altering the type of crystallization exhibited by the material and the size of the grain boundaries, which will in turn greatly influence the height of the potential barrier to hopping. ${ }^{8}$ The dipole orientation is also affected by the type of material crystallization, and by the presence of defects and imperfections in the material. ${ }^{10}$

The aim of the work presented herein is to examine the effect of tetra-tert-butyl peripheral functional groups on the conductivity and dielectric characteristics of the CuPc molecule. In particular, four tetra-tert-butyl groups are linked with four heterocycles of the CuPc molecule to form 2,9,16,23tetra-tert-butyl-29H,31H-copper phthalocyanine (CuTTBPc, Fig. 1). In fact, tert-butyl groups are widely applied as a peripheral group to fabricate functional compounds, including small organic molecules that exhibit good chemical stability, solubility, and light-fastness. ${ }^{11,12}$

The aim of this work is to study the influence of the peripheral groups on the dielectric properties

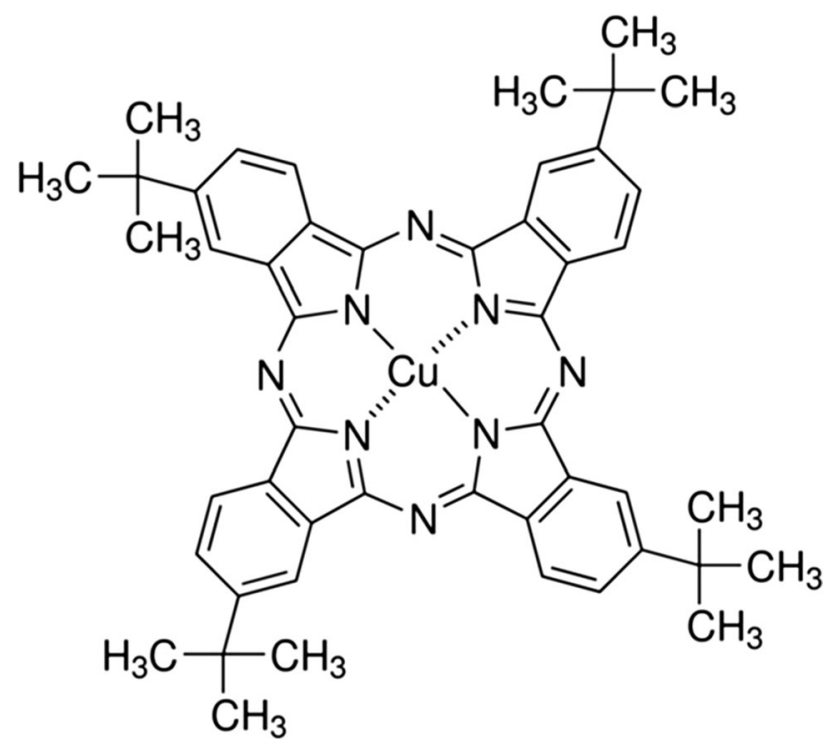

and electrical conductivity of the functional $\mathrm{CuPc}$ molecule using thin-film samples. The investigation of the AC conductivity of the semiconductor organic molecules enables a comprehensive description of the underlying hopping mechanism and the height of the potential barrier, ${ }^{13}$ whereas the dielectric properties of the material provide information about the relaxation mechanism and the possible longrange motion via carrier transitions in the lowfrequency regime. ${ }^{13}$

\section{EXPERIMENTAL PROCEDURES}

CuTTBPc powder with empirical formula $\mathrm{C}_{48} \mathrm{H}_{48} \mathrm{CuN}_{8}$ was purchased from Sigma Aldrich (Germany). The molecular weight of CuTTBPc is $800.49 \mathrm{~g} / \mathrm{mol}$, while the dye content is $97 \%$, and the melting point exceeds $300^{\circ} \mathrm{C}$. Successful evaporation of homogeneous CuTTBPc thin films on cleaned glass substrate was achieved using a vacuum vapor deposition technique. ${ }^{14,15}$ To achieve efficient gas evacuation, an HHV Auto 306 coating unit was applied for $2 \mathrm{~h}$ until pressure of $2.5 \times 10^{-4} \mathrm{~Pa}$ was obtained. A quartz-crystal thickness monitor was employed to maintain a deposition rate of $2 \mathrm{~nm} \mathrm{~s}^{-1}$. The thickness of the CuTTBPc thin films was calculated to be $150 \mathrm{~nm}$.

To explain the molecular structure of the powder as well as the as-grown CuTTBPc films, a Bruker Vector 22 was utilized to measure Fourier-transform infrared (FTIR) spectra in the range from $400 \mathrm{~cm}^{-1}$ to $4000 \mathrm{~cm}^{-1}$. A Philips X'Pert x-ray diffractometer using monochromatic $\mathrm{Cu} \mathrm{K}_{\alpha}$ radiation at $40 \mathrm{kV}$ and $25 \mathrm{~mA}$ was applied to study the film structure. For electrical measurements, CuTTBPc film was sandwiched between two electrodes of gold film with thickness of $100 \mathrm{~nm}$. Dielectric and $\mathrm{AC}$ conductivity measurements were carried out using a programmable Hioki 3532 HiTester automatic $R L C$ bridge. The impedance $(Z)$, capacitance $(C)$, and phase angle $(\phi)$ were evaluated in the frequency range from $50 \mathrm{~Hz}$ to $8 \mathrm{MHz}$ while the temperature of the sample was varied in the range from $293 \mathrm{~K}$ to $393 \mathrm{~K}$, as measured using a chromel-alumel thermocouple .

The total conductivity $(\sigma)$, dielectric constant $\left(\varepsilon_{1}\right)$, and dielectric loss $\left(\varepsilon_{2}\right)$ were calculated using the following equations:

$$
\begin{gathered}
\sigma=\frac{D}{Z A}, \\
\varepsilon_{1}=\frac{C D}{\varepsilon_{0} S}, \\
\varepsilon_{2}=\varepsilon_{2} \tan (\delta),
\end{gathered}
$$

where $D$ is the film thickness, $S$ is the film surface area, $\varepsilon_{0}$ is the free-space permittivity, and $\delta=90-\phi$.

Fig. 1. Molecular structure of CUTTBPc compound. 


\section{RESULTS AND DISCUSSION}

\section{Structural Characterization of CuTTBPc}

The FTIR spectra of the grown thin films, as well as the powder, are depicted in Fig. 2, revealing strong similarities between the spectra. Moreover, few differences were observed in the band intensity. For instance, the discrepancy of the band intensity at $1092 \mathrm{~cm}^{-1}$ and $2924 \mathrm{~cm}^{-1}$ is correlated to $\delta \mathrm{CH}$ and $v \mathrm{CH}_{3}$, respectively. The intensity of these bands declined for the as-deposited thin films, indicating weakening of the methylidyne radical $(\mathrm{CH})$ and the methyl group $\left(\mathrm{CH}_{3}\right)$ under the thermal effect. Such dissociation of free charge groups such as methylidyne radical $(\mathrm{CH})$ methyl group $\left(\mathrm{CH}_{3}\right)$ will cause an increase in the charge carrier density. Although thermal vacuum evaporation is considered to be a high-performance technique to avoid the interaction of the material with the vapor inside the chamber, a small trace of hydroxide group $\left(\mathrm{OH}^{-1}\right)$ remained inside the vacuum chamber. The increase of the intensity of the band at $3442 \mathrm{~cm}^{-1}$, related to $\mathrm{O}-\mathrm{H}$ stretching vibration, indicates the tendency of CuTTBPc vapor molecules to interact with this free hydroxide groups $\left(\mathrm{OH}^{-1}\right)$ inside the vacuum chamber. ${ }^{16}$

The absence of sharp diffraction peaks in the XRD pattern of the CuTTBPc film (Fig. 3) confirms its amorphous nature. In general, amorphous semiconductors can exhibit a wide variety of defect states in their bandgap. ${ }^{17}$ Such defects will produce several confined localized states for carrier charges between the valence and conduction bands of CuTTBPc. This phenomenon is expected to affect the activation energy and the height of the potential barrier between hopping sites. ${ }^{17}$ The characteristic features of amorphous organic films enable one to control the film thickness and easily deposit cumulative layers, resulting in a fabrication procedure that can produce materials with extremely high purity. ${ }^{18}$
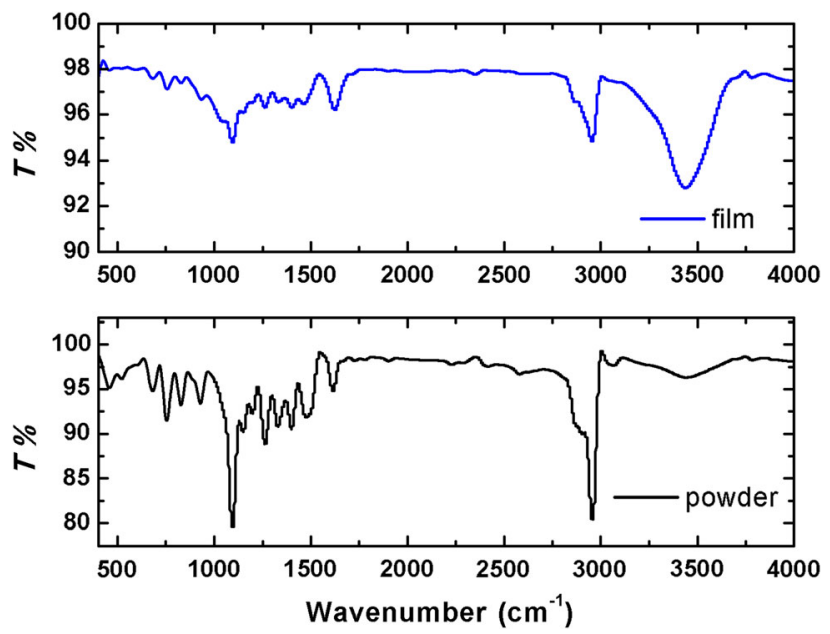

Fig. 2. FTIR spectra of CuTTBPc compound in powder and film form.
Finally, it is possible to deposit any organic semiconductor layers in the same direction on the grown amorphous film, resulting in organic materials that exhibit robust functionalities as well as utmost stability to the influence of an electric field. Understanding the mechanism of interior molecular orientation of such amorphous films is important, and several studies have shown that these molecules exhibit horizontal orientation depending on the anisotropy of the molecular configuration. ${ }^{8,19} \mathrm{Such}$ horizontal orientation is mostly recommended for use in organic light-emitting diodes (OLEDs), to ensure transport in the film thickness direction. ${ }^{20,21}$

\section{Dependence of Dielectric Loss $\left(\varepsilon_{2}\right)$ on Frequency and Temperature}

The dielectric characteristics of materials are mainly affected by the distortion (electronic and ionic) and relaxation (orientation and interfacial) polarization. ${ }^{22}$ Figure 4 illustrates the dependence

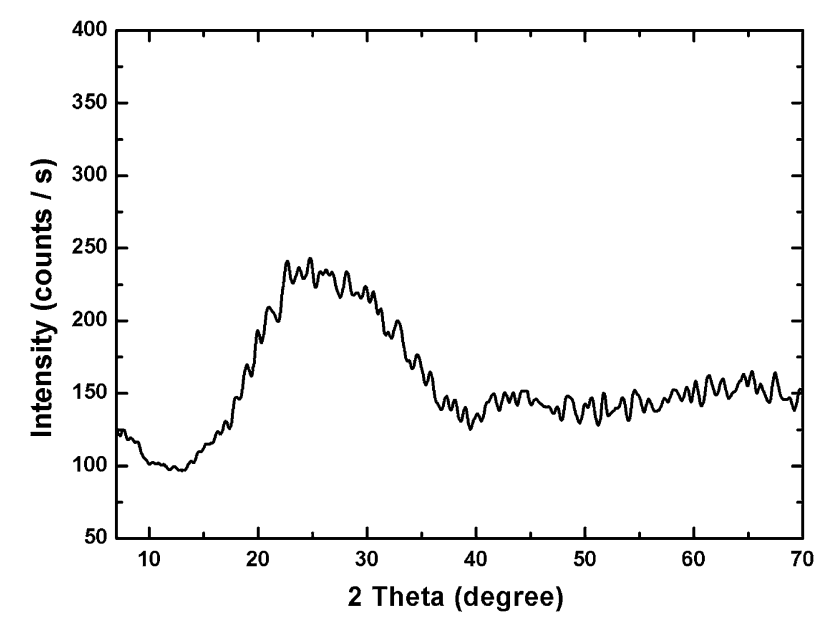

Fig. 3. XRD spectrum of CuTTBPc film.

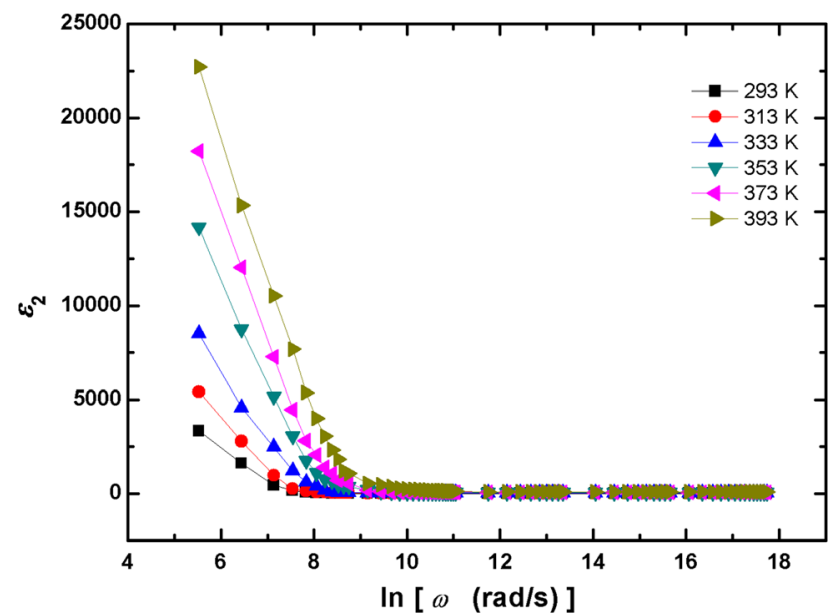

Fig. 4. Dielectric loss spectra of CuTTBPc films at different temperatures. 
of the dielectric loss spectrum $\left(\varepsilon_{2}\right)$ on frequency at various temperatures. In the low-frequency regime, large values of $\varepsilon_{2}$ are observed, but it decreases significantly as the frequency is increased. The dramatic decrease of $\varepsilon_{2}$ is highly desirable and actively sought for potential applications of such dielectric materials in electric energy storage capacitors and actuators. ${ }^{23}$ Eventually, in high-frequency regions, the value of $\varepsilon_{2}$ becomes invariant to increasing frequency, approaching a small, constant value in this region. The large values of $\varepsilon_{2}$ observed in the low-frequency regime can be attributed to the contributions of deformation and relaxation polarization. ${ }^{24}$

Subsequently, as the frequency is increased, the molecular dipoles of CuTTBPc can no longer rotate effectively with the direction of the electric field. ${ }^{25,26}$ Thus, the dipole orientation will delay the AC electric field. As the frequency is further increased, the dipoles will cease to follow the direction of the electric field, hence $\varepsilon_{2}$ approaches a constant value due to the contribution of deformation polarization only. ${ }^{25}$ Lastly, as expected, in the low-frequency regime, $\varepsilon_{2}$ increases as the temperature is increased. This behavior can be attributed to the thermal activation of orientation of molecular segments such as methyl groups. ${ }^{23,25}$

\section{Dielectric Modulus}

The electric modulus can be applied as an excellent tool for further exploration of the dielectric properties of the material. Such studies, carried out at various frequencies and temperatures, enable the differentiation between long-range charge transport and local dielectric relaxation. As a result, using the electric modulus can eliminate the relaxation contribution of impurity conduction effects, spacecharge injection phenomenon, and electrode effect, enabling the main source of electrical polarization in the material to be determined. ${ }^{15,27}$ The real and imaginary parts of the complex electric modulus $\left(M_{1}\right.$ and $M_{2}$ ) can be evaluated using the following equations: ${ }^{7}$

$$
\begin{aligned}
& M_{1}(\omega)=\frac{\varepsilon_{1}}{\varepsilon_{1}^{2}(\omega)+\varepsilon_{2}^{2}(\omega)}, \\
& M_{2}(\omega)=\frac{\varepsilon_{2}}{\varepsilon_{1}^{2}(\omega)+\varepsilon_{2}^{2}(\omega)} .
\end{aligned}
$$

Figure 5 shows the variation of the moduli $M_{1}$ and $M_{2}$ versus frequency at different temperatures. Figure 5 shows the tendency of both $M_{1}$ and $M_{2}$ to approach zero in the low-frequency regime, indicating a negligible electrode effect. ${ }^{28}$ Moreover, as shown in Fig. $5 \mathrm{~b}$, the relaxation peaks are shifted towards higher frequency as the temperature was increased. This result confirms that the relaxation mechanism was significantly affected by the
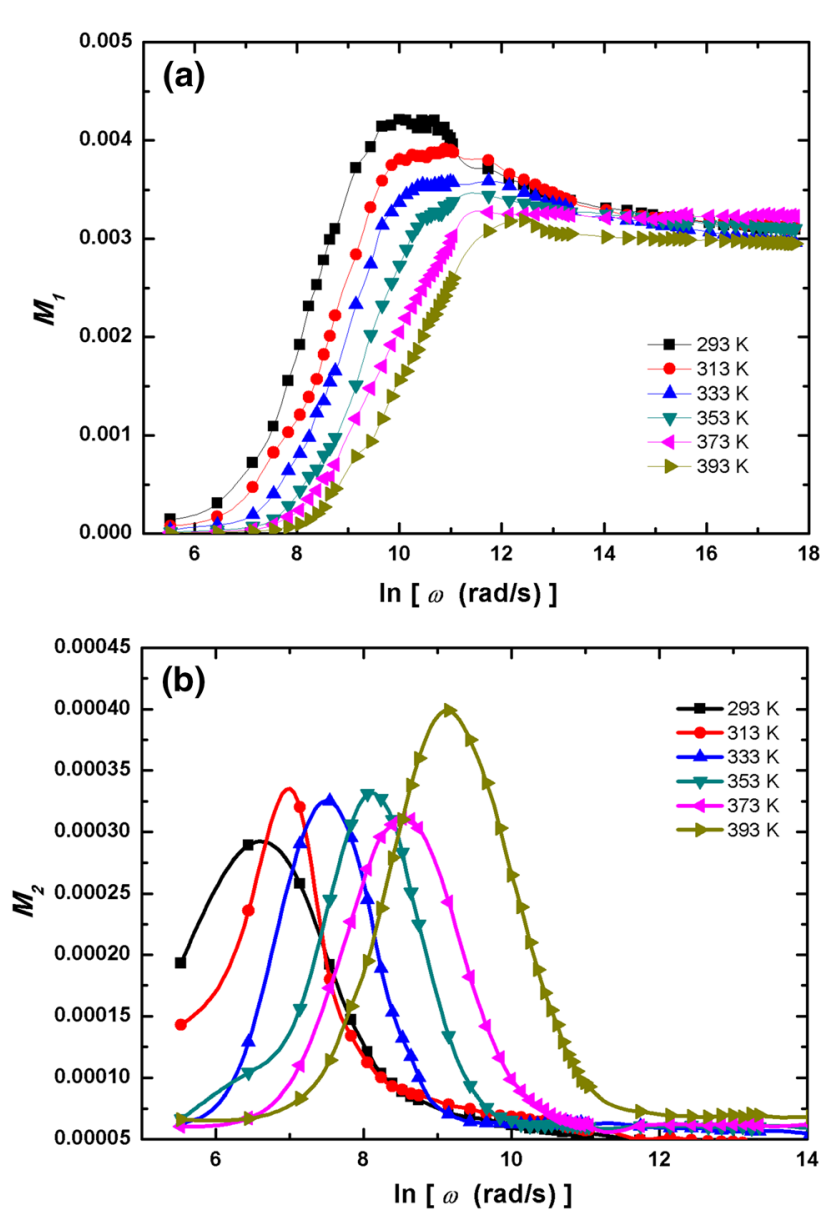

Fig. 5. Spectra of (a) real and (b) imaginary parts of the dielectric module for CUTTBPc films at different temperatures.

thermal activation process. ${ }^{29}$ On the other hand, long-range transport of charge carries is only permitted in the frequency domain below the maximum relaxation peak of $M_{2} \cdot{ }^{30}$ At higher frequency exceeding the correlated frequency of the maximum peak, the depth of the potential barrier becomes greater. Consequently, ionic groups and free-radical segments can move only short distances due to the high confining potential well. ${ }^{31}$

The relaxation time, $\tau_{\mathrm{m}}$, can be determined from the correlated frequency of the highest maximum peak $\left(\tau_{\mathrm{m}}=\omega_{\mathrm{m}}^{-1}\right)$, whereas the activation energy of the relaxation process can be evaluated from the Arrhenius equation: ${ }^{10}$

$$
\tau_{\mathrm{m}}=\tau_{0} \exp \left(\frac{\Delta E_{\mathrm{M}}}{K_{\mathrm{B}} T}\right)
$$

where $K_{\mathrm{B}}$ is the Boltzmann constant, $\Delta E_{\mathrm{M}}$ is the activation energy of the relaxation process, and $\tau_{\mathrm{o}}$ is the pre-exponential factor. A plot of $\ln \tau_{\mathrm{m}}$ versus reciprocal temperatures is shown in Fig. 6. The values of $\Delta E_{\mathrm{M}}$ were calculated from the slope of the fitting line, whereas the value of $\tau_{0}$ was determined from the intersection of the plotted line with the $\ln \tau$-axis. The values of $\Delta E_{\mathrm{M}}$ and $\tau_{0}$ were thus estimated to be $0.26 \mathrm{eV}$ and $5.6 \times 10^{-8} \mathrm{~s}$, 


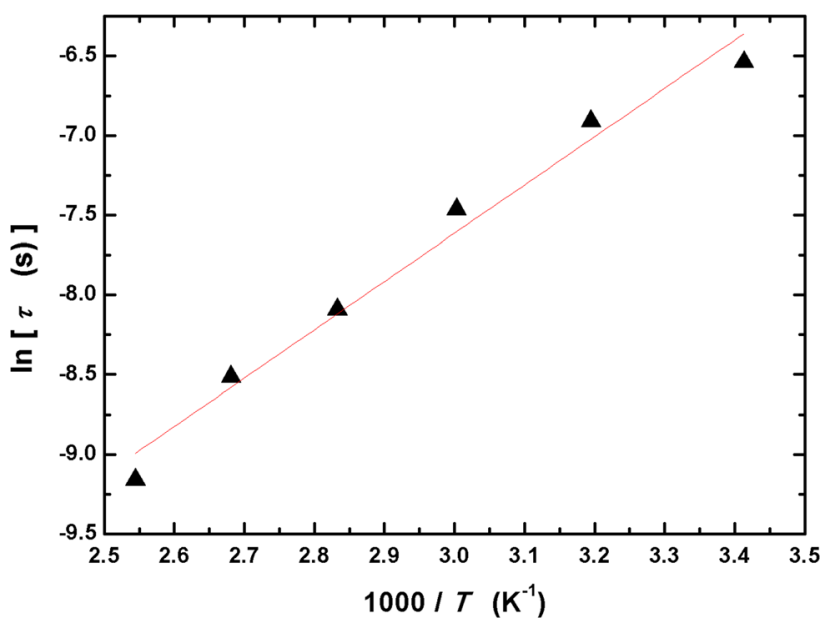

Fig. 6. Reciprocal temperature dependence of $\tau$ for CuTTBPc films.

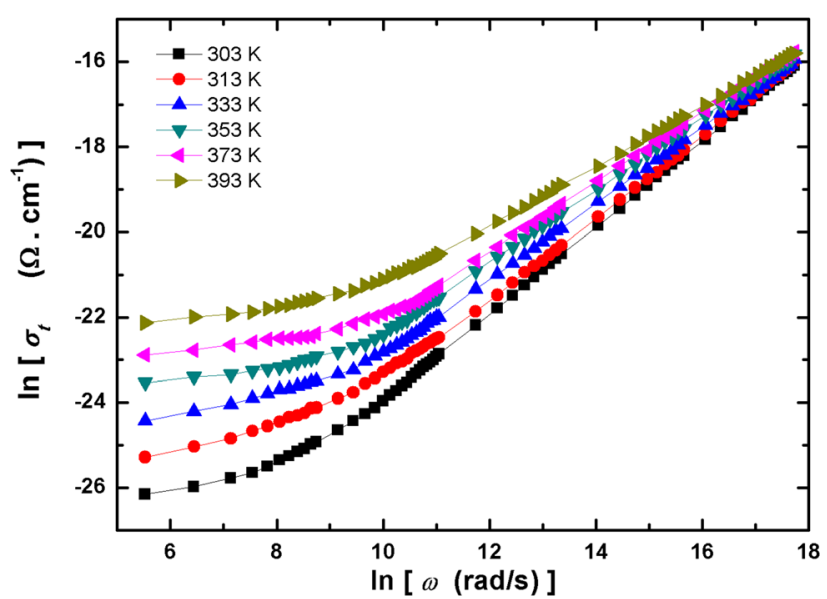

Fig. 7. Total conductivity spectra of CuTTBPc films at different temperatures.

respectively. This extracted value of $\Delta E_{\mathrm{M}}$ is compatible with results reported for large numbers of small organic molecules. $7,10,15,23,27-29$

\section{AC Conductivity}

The electrical conductivity $(\sigma)$ provides an insight into the carrier charge mechanism operating within a material. Figure 7 shows the relationship between $\sigma$ and frequency at various temperatures, where two separate frequency regimes can be distinguished. In the low-frequency regime, i.e., below a critical frequency $\left(\omega_{c}\right)$, the conductivity shows only slight dependence on frequency; such a region is correlated with the DC conductivity. Meanwhile, above the critical frequency region, the conductivity depends strongly on frequency; such a region is dominated by the AC conductivity. ${ }^{27}$ These characteristic features have been clearly observed for many organic molecules. $^{7,10,15,23,25,30,31}$ Furthermore, the frequency dependence in the $\mathrm{AC}$ conductivity regime can be explained by Jonscher's power law: ${ }^{23}$
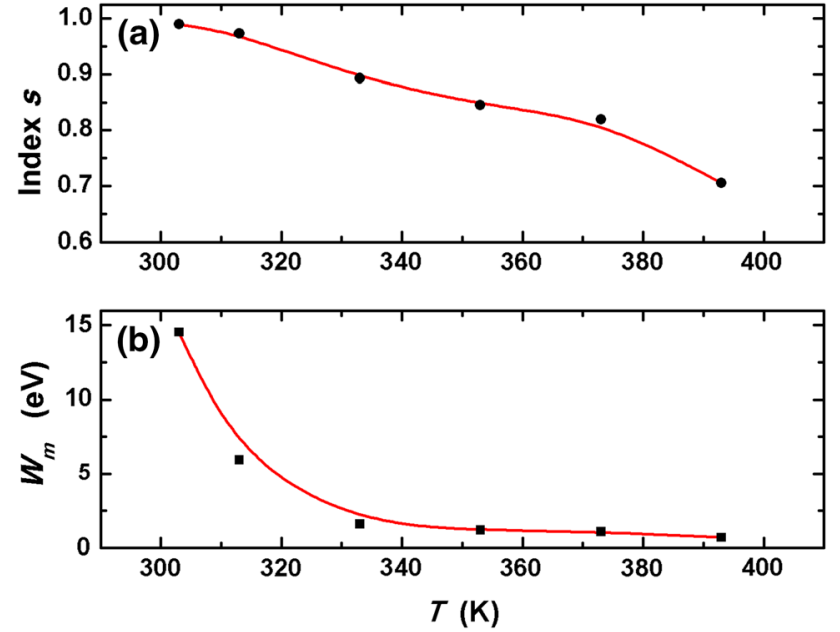

Fig. 8. Values of (a) exponent $(s)$ and (b) $W_{m}$ as functions of temperature for CuTTBPc films.

$$
\sigma_{\mathrm{AC}}=A \omega^{s},
$$

where $A$ is a variable that depends on the temperature and the material structural. The exponent $(s)$, which can be evaluated from the slope of the line plotted in Fig. 7, is usually taken to be an essential criterion to determine the carrier charge transport mechanism. The variation of $s$ with temperature, as shown from Fig. 8a, exhibits two remarkable behaviors of $s$ : (1) $s$ decreases as the temperature is increased, and (2) the value of $s$ remains below 1 , confirming the appropriateness of the correlated barrier hopping (CBH) model. ${ }^{7,10,15,23,27,29}$ In this model, charge transport mainly occurs due to hopping of charges between the two sides of the potential barrier. These findings are in agreement with several reports that investigated the charge transport mechanism in Pc molecules; For instance, Vidadi et al. showed that the value of this exponent for $\mathrm{MgPc}$ thin films reached a maximum value of 1.75 , at high frequencies. ${ }^{32}$ Such a high value above unity is due to the steady transition from the extended hopping area to another one which is dominated by two hopping centers. On the other hand, James et al. pointed out that the value of $s$ for $\mathrm{MoOPc}$ is about 0.9 at room temperature, thus validating only the $\mathrm{CBH}$ model for carrier charge transport. ${ }^{33}$

According to the $\mathrm{CBH}$ model, the maximum height $\left(W_{\mathrm{m}}\right)$ of the potential barrier can be determined by substituting the value of $s$ into the equation $^{15}$

$$
s=1-\left(6 K_{\mathrm{B}} T / W_{\mathrm{m}}\right) .
$$

Figure $8 \mathrm{~b}$ shows the dependence of $W_{\mathrm{m}}$ on temperature, revealing that the maximum height declines as the temperature is increased. Thus, the hopping of carrier charges increases as the temperature is increased. According to the $\mathrm{CBH}$ model, the 


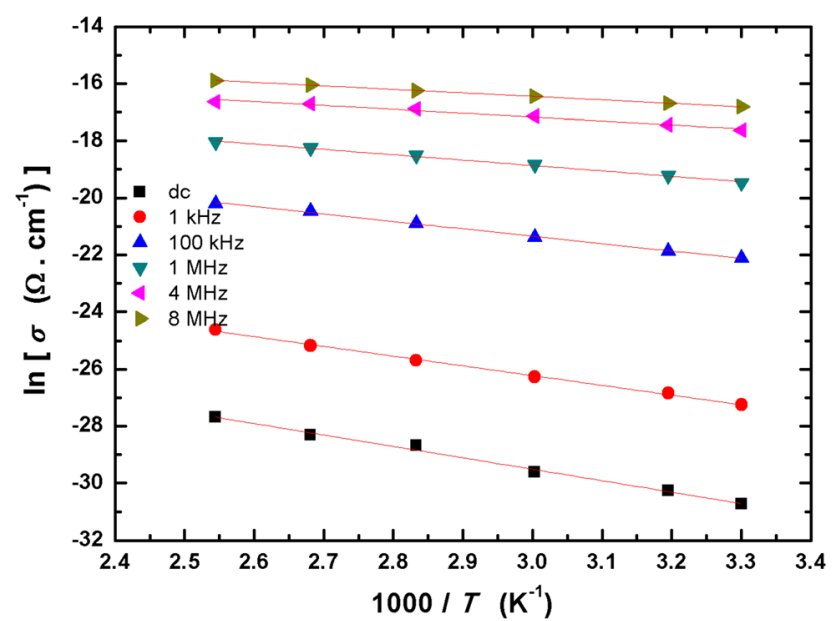

Fig. 9. Variation of $\ln \sigma$ with $1000 / T$ for CuTTBPc films at different frequencies.

density of localized states close to the Fermi energy $N\left(E_{\mathrm{F}}\right)$ can be evaluated from the equation ${ }^{34}$

$$
\sigma_{\mathrm{AC}}(\omega)=\frac{\pi}{3} e^{2} T N^{2}\left(E_{\mathrm{F}}\right) \omega L_{\mathrm{LOC}}^{5} \ln \left(\frac{1}{\omega \tau_{0}}\right),
$$

where $L_{\mathrm{LOC}}(\sim 10 \AA)$ is the charge localization state $^{34}$ and $\tau_{0}\left(\sim 10^{-13} \mathrm{~s}\right)$ is the order of an atomic vibration period. ${ }^{34} N\left(E_{\mathrm{F}}\right)$ at $T=293 \mathrm{~K}$ and frequency $500 \mathrm{kHz}$ is found to be $4.11 \times 10^{23} \mathrm{eV}^{-1} \mathrm{~cm}^{-3}$. The value of the localized density of states for this material can be compared with some fabricated heterojunction organic compounds. For instance, the density of states of the $\mathrm{AlPcCl}$ and $\mathrm{p}-N, N$ dimethylamino benzylidene malononitrile (DBM) organic dyes at $T=293 \mathrm{~K}$ and frequency of $500 \mathrm{kHz}$ was found to be $3.54 \times 10^{20} \mathrm{eV}^{-1} \mathrm{~cm}^{-3}$ and $3.24 \times 10^{20} \mathrm{eV}^{-1} \mathrm{~cm}^{-3}$, respectively. ${ }^{7,35}$ Therefore, this high density of electron states of the CuTTBPc compound suggests the possibility of its use in solar cell applications.

The temperature dependence of $\sigma$ at different frequencies is depicted in Fig. 9, clearly revealing that $\sigma$ is directly proportional to reciprocal temperature. This proportionality is due to the thermal activation of charge hopping between the sides of the potential. ${ }^{15,36}$ Similar observations have also been found for various other inorganic $c^{13,37,38}$ as well as organic materials. 7,10,15,23,27,29 In general, the activation energy can be calculated by using the Arrhenius equation $^{23}$ :

$$
\sigma_{\mathrm{AC}}=\sigma_{0}\left(\frac{-\Delta E}{K_{\mathrm{B}} T}\right)
$$

where $\sigma_{o}$ is the pre-exponential factor. Figure 10 shows a decline in the activation energy as the frequency is increased. Hence, an increase of the frequency enhances the jumping of electrons between the hopping sites of the localized states. This phenomenon, which is consistent with results obtained for many organic molecules, $7,10,15,23,27,29$

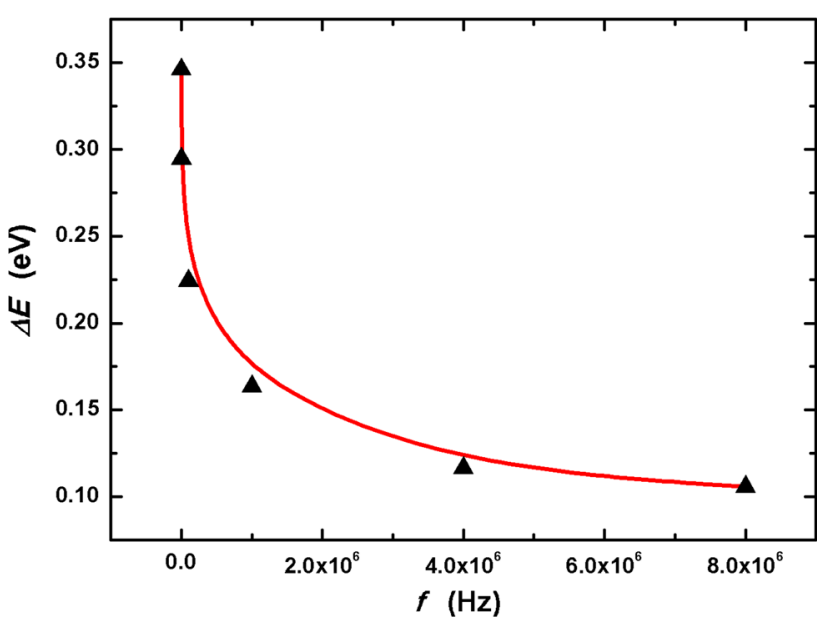

Fig. 10. Activation energy as function of frequency for CuTTBPc films.

verifies that the $\mathrm{CBH}$ model is appropriate to investigate the carrier charge transport mechanism of CuTTBPc thin films.

\section{CONCLUSIONS}

The dielectric behavior and electrical conductivity of CuTTBPc films were investigated as functions of frequency and temperature. The dependence of the dielectric relaxation spectra on the frequency at different temperatures was measured and is discussed. The dielectric properties of CuTTBPc film in the low-frequency regime are affected by the deformation polarization and relaxation polarization. In addition, the spectral dynamics of both the real and imaginary parts of the complex electric modulus was studied over a wide temperature range. Additionally, the spectra of the imaginary part of the dielectric modulus confirmed that the relaxation response is significantly affected by the thermal activation process. The AC conductivity of the CuTTBPc thin films verified that the predominant charge transport mechanism can only be described using the correlated barrier hopping $(\mathrm{CBH})$ model.

\section{CONFLICT OF INTEREST}

The authors declare that they have no conflicts of interest.

\section{REFERENCES}

1. N. Bouazizia, S. Louhichia, R. Ouarglic, R. Bargouguid, J. Vieillard, F. Le Derfa, and A. Azzouze, Appl. Surf. Sci. 404, 146 (2017).

2. N. Bouazizi, F. Ajala, A. Bettaibi, M. Khelil, A. Benghnia, R. Bargougu, S. Louhichi, L. Labiadh, R. Ben Slama, B. Chaouachi, K. Khiroun, A. Houas, and A. Azzouz, J. Alloys Compd. 656, 146 (2016).

3. T. An, W. Gong, and J. Ma, Org. Electron. 67, 320 (2019).

4. M.M. El-Nahass and K.F. AbdEl-Rahman, J. Alloys Compd. 430, 194 (2007)

5. S.I. Qashou, A.A.A. Darwish, and S.E. Al Garni, Synth. Met. 242, 67 (2018).

6. A.A.A. Darwish, S.I. Qashou, Z. Khattari, M.M. Hawamdeh, A. Aldrabee, and S.E. Al Garni, J. Electron. Mater. 47, 7196 (2018). 
7. I.M. Soliman, M.M. El-Nahass, and Y. Mansour, Solid State Commun. 225, 17 (2016).

8. Z.T. Deng, H.M. Guo, W. Guo, L. Gao, Z.H. Cheng, D.X. Shi, and H.-J. Gao, J. Phys. Chem. C 113, 11223 (2009).

9. R.D. Gould and A.K. Hassan, Thin Solid Films 223, 334 (1993).

10. M.M. El-Nahass, E.F.M. El-Zaidia, A.A.A. Darwish, and G.F. Salem, J. Electron. Mater. 46, 1093 (2017).

11. J.W. Perry, K. Mansour, I.-Y.S. Lee, X.-L. Wu, P.V. Bedworth, C.-T. Chen, D. Ng, S.R. Marder, P. Miles, T. Wada, M. Tian, and H. Sasabe, Science 273, 1533 (1996).

12. A.A.A. Darwish, S.I. Qashou, and M. Rashad, Appl. Phys. A 125, 271 (2019).

13. A.A.A. Darwish, E.F.M. El-Zaidia, M.M. El-Nahass, T.A. Hanafy, and A.A. Al-Zubaidi, J. Alloys Compd. 589, 393 (2014).

14. S.I. Qashou, M. Rashad, A.Z. Mahmoud, and A.A.A. Darwish, Vacuum 162, 199 (2019).

15. S.I. Qashou, A.A.A. Darwish, M. Rashad, and Z. Khattari, Phys. B 525, 159 (2017).

16. N. Bouazizi, R. Bargougui, A. Benghnia, J. Vieillard, S. Ammar, and A. Azzouz, RSC Adv. 6, 95405 (2016).

17. Matthias Kaes and Martin Salinga, Sci. Rep. 6, 31699 (2016).

18. D. Yokoyama, J. Mater. Chem. 21, 9187 (2011).

19. A.P. Kulkarni, C.J. Tonzola, A. Babel, and S.A. Jenekhe, Chem. Mater. 16, 4556 (2004).

20. Y. Shirota and H. Kageyama, Chem. Rev. 107, 953 (2007).

21. L. Xiao, Z. Chen, B. Qu, J. Luo, S. Kong, Q. Gong, and J. Kido, Adv. Mater. 23, 926 (2011).

22. R.P. Jebin, T. Suthan, N.P. Rajesh, and G. Vinitha, Opt. Laser Technol. 115, 500 (2019).

23. X. Li, W. Xua, Y. Zhang, D. Xub, G. Wanga, and Z. Jianga, RSC Adv. 5, 51542 (2015).
24. S.I. Qashou, A.A.A. Darwish, S.R. Alharbi, S.E. Al Garni, and T.A. Hanafy, J. Mater. Sci: Mater. Electron. 28, 14252 (2017).

25. S. Zhong, J.Q. Zhong, A.T.S. Wee, and W. Chen, J. Electron Spectrosc. Relat. Phenom. 204, 12 (2015).

26. R. Bargougui, N. Bouazizi, S. Ammar, and A. Azzouz, J. Electron. Mater. 46, 85 (2017).

27. E.M. El-Menyawy, H.M. Zeyad, and M.M. El-Nahass, Solid State Sci. 12, 2182 (2010).

28. F.S. Howell, R.A. Bose, P.B. Maced, and C.T. Moynihan, Phys. Chem. 78, 639 (1974).

29. T.A. Abdel-Baset and A. Hassen, Phys. B 499, 24 (2016).

30. A.A. Attia, H.S. Soliman, M.M. Saadeldin, and K. Sawaby, Synth. Met. 205, 139 (2015).

31. M.M. El-Nahass and H.A.M. Ali, Solid State Commun. 152, 1084 (2012).

32. YuA Vidadi, L.D. Rozenshtein, and E.A. Chistyakov, Sov. Phys. Solid State 11, 173 (1969).

33. S.A. James, A.K. Ray, and S. Silver, Phys. Status Solidi A 129, 435 (1992).

34. A.O. Abu-Hilal, A.M. Saleh, and R.D. Gould, Mater. Chem. Phys. 94, 165 (2005).

35. M.M. El-Nahass, A.A. Atta, M.A. Kamel, and S.Y. Huthaily, Vacuum 91, 14 (2013).

36. N. Bouazizi, F. Ajala, M. Khelil, H. Lachheb, K. Khirouni, A. Houas, and A. Azzouz, J. Mater. Sci. Mater. Electron. 27, 11168 (2016).

37. G. Singh, N. Goyal, G.S.S. Saini, and S.K. Tripathi, J. NonCryst. Solids 353, 1322 (2007).

38. V. Modgil and V.S. Rangra, Phys. B 445, 14 (2014).

Publisher's Note Springer Nature remains neutral with regard to jurisdictional claims in published maps and institutional affiliations. 